\title{
IMF Data Standards Initiatives: A Consultative Approach To Enhancing Global Data Transparency
}

Anne Y. Kester 



\title{
IMF Working Paper
}

Statistics Department

\section{IMF Data Standards Initiatives: A Consultative Approach To Enhancing Global Data Transparency \\ Prepared by Anne Y. Kester ${ }^{1}$}

Authorized for distribution by Kimberly D. Zieschang

April 2006

\begin{abstract}
This Working Paper should not be reported as representing the views of the IMF. The views expressed in this Working Paper are those of the author(s) and do not necessarily represent those of the IMF or IMF policy. Working Papers describe research in progress by the author(s) and are published to elicit comments and to further debate.

Since the IMF launched the data standards initiatives a decade ago, 145 of its 184 member countries have participated. This 80 percent participation rate reaffirms the importance countries place on data transparency in the globalized economy, which the initiatives promote. The wide participation can be attributed to the consultative process that has allowed for the development of a coherent program that takes account of countries' capabilities, delineates clear responsibilities between the IMF and participating countries, and establishes effective monitoring procedures to ensure the credibility of the standards for policymakers, capital markets, and the general public. The approach has also provided checks and balances and fostered accountability. The initiatives may provide insights for the promotion of similar international standards.

JEL Classification Numbers: G3, G10, G14, G15

Keywords: Surveillance, data standards, Special Data Dissemination Standard, General Data Dissemination System, Dissemination Standards Bulletin Board, international standards

Author(s) E-Mail Address: akester@imf.org

\footnotetext{
1 The author wishes to thank Robert Edwards and Kimberly Zieschang for their comments and suggestions and to Tessa van der Willigen and Claudia Dziobek for their review of an earlier draft. The paper has also benefited from assistance from Anthony Pellechio, Alain Brousseau, Zdravko Balyozov, Louis Venter, Angel Sanchez, Norma Marotta, Sheridan Parsonson, and Catherine Braganza.
} 


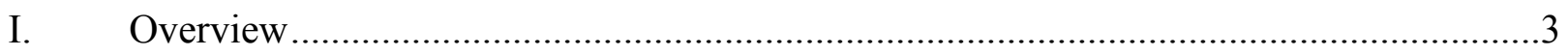

II. Consultations Shape the Design of the SDDS and the GDDS....................................4

III. Key Features and Clear Responsibilities Promote Credibility of the SDDS and

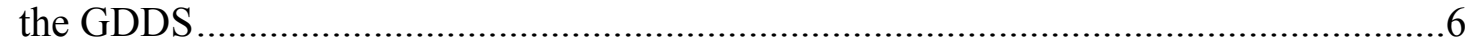

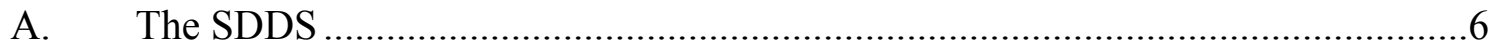

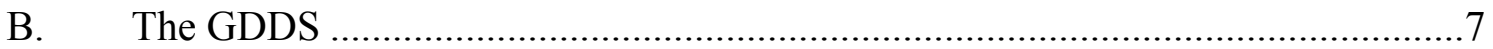

C. Differences Between the SDDS and the GDDS .......................................

D. Dissemination Standards Bulletin Board ........................................................

IV. Executive Board Reviews Support Enhancements and Foster Accountability ...............9

V. A Comprehensive Work Program Supports Steady Implementation of the SDDS and

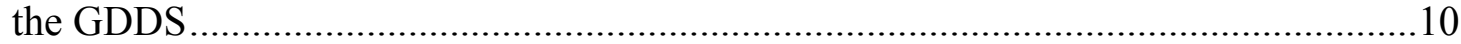

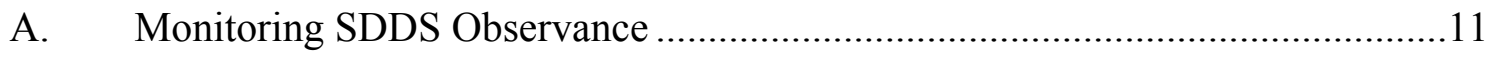

B. Conferences, Seminars, and Other Consultations............................................11

C. Other Collaborative Efforts.................................................................. 12

VI. Useful Guidelines Help Participation and Observance............................................12

VII. Increased Participation Advances Global Data Transparency ....................................13

Appendices

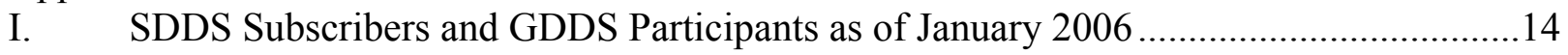

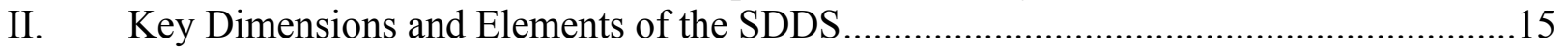

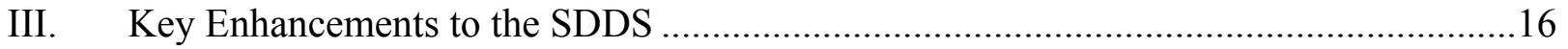




\section{OVERVIEW}

This paper highlights the process of consultation used in conjunction with the International Monetary Fund's data transparency standards, the Special Data Dissemination Standard (SDDS) and the General Data Dissemination System (GDDS). The paper underscores that the standards to date have attained their intended results by adhering to several key principles of sound consultation: taking account of countries' capabilities, clearly delineating the responsibilities of the IMF and participating countries, establishing effective monitoring procedures, and managing the consultation within a dedicated work program that has been reviewed periodically to ensure its transparency and accountability. The paper also notes that the experience of the IMF with these principles has broader applicability for other international standards that exist to promote cooperation among countries in various economic and financial areas.

The IMF launched the data standards initiatives a decade ago to enhance member countries' data transparency and to promote their development of sound statistical systems to inform public and private decision making. The need for data standards was highlighted by the financial crises of the 1990s, in which information deficiencies were seen to play a role. The initiatives cover the SDDS and the GDDS. The SDDS guides countries that have or seek access to capital markets to disseminate key data so that users in general, and financial market participants in particular, can better assess the economic situations of individual countries. The GDDS provides countries seeking to develop their statistical systems a framework within which to work toward disseminating comprehensive and reliable data that, among other things, meet SDDS requirements.

The design and the implementation of the SDDS and the GDDS have been marked by extensive internal and external consultation. The consultative process inevitably has been time-consuming and resource-intensive, but it has been essential to advance the standards and contribute to their success in promoting the global practice of data transparency. Enhanced data transparency, in turn, has facilitated macroeconomic policymaking and the improved functioning of financial markets.

Since their inception, the SDDS and the GDDS have been part of the work program of the IMF Statistics Department (STA). The work program has been coordinated with other IMF departments and reviewed periodically by the IMF Executive Board. To establish sound data dissemination practices and to promote their adoption by countries, as promulgated by the initiatives, STA has conducted outreach and technical assistance programs. In addition, in support of these initiatives, the IMF has established and maintained the Dissemination Standards Bulletin Board (DSBB) to provide users ready access to economic and financial data disseminated by countries that subscribe to the SDDS or participate in the GDDS. Over time, as endorsed by its Executive Board, the IMF has enhanced these standards by incorporating in them methodological developments in various areas of macroeconomic statistics, as set forth in manuals and guidelines the IMF has published. The enhancements have promoted consistency between the dissemination standards and other statistical guidelines and frameworks, facilitating their implementation in countries. 
Furthermore, to support developing countries' pursuit of the Millennium Development Goals and poverty-reduction programs, the IMF has collaborated with the World Bank and other donor agencies to include selected social and demographic data categories and related guidelines in the IMF's data transparency standards. It has also assisted countries in implementing them.

To date, 62 IMF member countries are SDDS subscribers and another 83 are GDDS participants, together accounting for 80 percent of the IMF membership (see Appendix I). Anecdotal evidence and empirical studies suggest that subscription to the SDDS or participation in the GDDS, to varying extents, can improve a country's access to international capital markets. The number of member countries participating in the GDDS has also underscored the significant role the GDDS can play in providing a sound framework for the development of national statistical systems. In fact, a number of GDDS countries, by improving their statistical systems, have graduated to become SDDS subscribers. In addition, the availability of timely, accurate, and comprehensive information on the economic and financial conditions of SDDS and GDDS countries, accessible on the Internet at the IMF's DSBB, has also facilitated country analyses and related risk assessments undertaken by various users.

Looking ahead, as participation in the data standards initiatives reaches almost the entire IMF membership, the consultative approach will even be more important. With increased participation and with tight resources, ensuring the effective monitoring of observance of the SDDS and the tracking of statistical developments of GDDS countries will require the continued cooperation of participating countries. In addition, in a globalized economy, regular consultations among data producers and users will be essential to facilitate the production and dissemination of relevant, consistent, accurate, and timely data to inform public policymaking and to meet users' emerging data needs. Such consultations in most cases will work best when managed within specific work programs.

The rest of this paper elaborates on the consultative process used in establishing the SDDS and the GDDS, in determining responsibilities of the participating countries and of the IMF, and in shaping a coherent program to implement the standards. It also discusses efforts the IMF has made, in consultation with members, to maintain and strengthen the credibility of the standards.

\section{CONSUltations SHAPE THE DESIGN OF THE SDDS AND THE GDDS}

The IMF's work on data dissemination standards began in October 1995, in the aftermath of the Mexican financial crisis, when the Interim Committee (now the International Monetary and Financial Committee) endorsed the IMF's establishment of standards to guide members in the dissemination to the public of their economic and financial data. The standards were to consist of two tiers: the SDDS to guide countries that have, or that might seek, access to international capital markets, and the GDDS to assist all other member countries. The IMF Executive Board approved the SDDS in March 1996 and the GDDS, in December 1997. 
The IMF used a wide-ranging consultative process in establishing and implementing the standards. Internally, it involved the IMF Executive Board and various departments, in particular, STA. Externally, the consultation extended beyond the usual counterparts of the IMF staff in finance ministries and central banks and involved data producers in countries, statistical experts in international agencies, data users in the financial markets and elsewhere, and private analysts and experts. The process evolved as follows:

- Initially, from April to September 1995, consultation on the design of the SDDS took place through Board papers, ${ }^{2}$ generating feedback through Executive Directors from their respective countries' finance ministries, central banks, and statistical agencies. This, in turn, led to follow-up papers.

- The second phase involved a round of missions to 24 countries from October to December 1995, which entailed discussions both with producers of economic and financial statistics (typically economics and finance ministries, central banks, and statistical agencies) and with private-sector representatives (banks, other financial houses, credit-rating agencies, think-tanks, economic analysts, and others). The IMF staff corresponded with another 42 countries on the design of the SDDS on the basis of a detailed questionnaire. The discussions and contacts with these parties provided information on the needs of data users, the perspectives of data compilers, and countries' statistical priorities and constraints.

- Phase three in February 1996 involved a discussion paper released to the media, made available on the IMF Web site, and sent for comment to some 7,000 entities, including market participants, country authorities, international organizations, and other interested parties. Among international organizations consulted were the European Monetary Institute (the forerunner of the European Central Bank), EUROSTAT, the United Nations Statistics Division, the Organization of Economic Cooperation and Development (OECD), the United Nations Economic Commission for Europe, the United Nations Economic and Social Commission for Asia and Pacific, and the United Nations Economic Commission for Latin America and the Caribbean. The comments received were considered in the design of the SDDS and GDDS.

- The fourth phase comprised a further round of Board papers, followed by the approval and implementation of the SDDS in March 1996. Once the Board approved the SDDS, letters inviting subscription were sent to member countries and regional seminars were held. Fifty-three countries sent teams to seminars the IMF held in Asia, Europe, and Latin America between June and August 1996. At these seminars, the IMF staff guided country practitioners through the requirements of the SDDS, the modalities of subscription, and the steps involved in the preparation of country

\footnotetext{
${ }^{2}$ Board papers are those the IMF staff prepares for discussion by the IMF Executive Board, whose endorsement is sought for certain IMF work programs.
} 
metadata (information on country statistical methods and practices) for posting on the IMF's DSBB, which was created to provide users ready access to such information of subscribing countries.

- The Executive Board was given a preview of the DSBB before it was made available to the public. The DSBB first appeared on the IMF Web site in September 1996. The IMF publicized the inception of the DSBB with events in London, Singapore, and Tokyo. In April 1997, hyperlinks were introduced from the DSBB to country Web sites of SDDS subscribers, providing users with convenient access to the countries' economic and financial data.

- Once member countries began subscribing to the SDDS and the DSBB was made available to the public, the IMF staff was in regular contact with country officials involved in SDDS-related activities, international agencies, and DSBB users. A voluntary registration system was established for DSBB users in June 1997 to provide information about the system's users and to facilitate continued dialogue with them.

- The Executive Board considered the design of the GDDS in March 1997 and formally approved it in December 1997. As was established for SDDS subscribing countries, in May 2000 the IMF added a GDDS site on the DSBB to inform the public about countries participating in the GDDS, including their current statistical practices and their plans for development of their statistical systems within the GDDS framework.

\section{Key features and Clear Responsibilities Promote Credibility of the SDDS AND THE GDDS}

Both the SDDS and the GDDS are intended to enhance the availability of timely and comprehensive statistics, thereby contributing to the pursuit of sound macroeconomic policies. In addition, the SDDS is expected to contribute to the improved functioning of financial markets. The design of the SDDS and the GDDS is largely a product of the consultative process, reflecting feedback from various sources, as noted above. One key feature of the data standards initiatives is that a country's subscription to the SDDS or its participation in the GDDS is voluntary. Nonetheless, subscription to the SDDS or participation in the GDDS requires a country to observe certain requirements as set forth in the SDDS and the GDDS.

\section{A. The SDDS}

The SDDS covers four dimensions of data dissemination: (1) data coverage, periodicity, and timeliness, (2) the public's access to the data, (3) the integrity of the disseminated data, and (4) the quality of the disseminated data. For each of these dimensions, the SDDS prescribes good practices that can be observed or monitored by the users of statistics (see Appendix II). With respect to data coverage, periodicity, and timeliness, the SDDS prescribes that 22 categories of data be disseminated, each at a specific frequency and with a prescribed timeliness, to meet the minimum requirements of the standard; these data cover national accounts and prices, government operations, monetary and 
financial activities, and external transactions. With respect to data access, integrity, and quality, the SDDS prescribes practices that promote transparency and easy access. Consistent with this approach, dissemination is to include electronic dissemination in addition to more traditional modes.

The SDDS requires subscribing countries to disseminate the prescribed data on a timely and regular basis, as set forth in the standard, on the subscribing country's national Web site designated as the "National Summary Data Page" (NSDP). It also calls for subscribing countries to provide to the IMF certain types of information about their practices (metadata) in disseminating economic and financial data, for posting on the IMF's DSBB.

The IMF is to maintain the DSBB as a service to the public. The IMF staff reviews subscribing countries' metadata for comprehensiveness and international comparability. The responsibility for the accuracy of the metadata (including timely updates) and for the economic and financial data underlying the metadata rests with the subscribing country. In addition, subscribers are required to certify on a quarterly basis the accuracy of all metadata posted on the DSBB. The SDDS metadata are to provide insights into the usefulness and limitations of the published data.

The IMF staff is to regularly monitor subscribers' observance of the standard. Such monitoring is facilitated by the information countries provide, which the IMF posts on the DSBB, as well as by the data countries disseminate on their NSDPs. A member's presence on the DSBB as a subscriber to the SDDS indicates its intention to observe certain tenets of good statistical citizenship. Serious and persistent nonobservance of the SDDS is a cause for action. The Executive Board of the IMF has approved procedures to be followed in instances of such nonobservance.

\section{B. The GDDS}

The GDDS is a framework that guides countries in developing sound statistical systems as the basis for disseminating data to the public. The GDDS addresses the full range of issues critical to compiling and disseminating data and making explicit plans to align national procedures with best practices. As in the SDDS, four dimensions of data compilation and dissemination are covered in the GDDS framework: (1) data coverage, periodicity, and timeliness; (2) the public's access to the data; (3) the integrity of the disseminated data; and (4) the quality of the disseminated data.

The GDDS requires participating countries to prepare metadata on their current statistical practices, to develop their plans for improvement in the near and medium term, and to identify associated needs for technical assistance in implementing these plans.

Participating countries must update their metadata at least annually to describe how their data compilation and dissemination activities are keeping pace with the best statistical practices. The DSBB also disseminates metadata of GDDS participating countries. 
The GDDS calls for the national authorities to set their own priorities and timing for developing their statistical systems. It allows the data-producing agencies to take control of their statistical development programs in a structured manner and to coordinate effectively among producing agencies, users, and the international community. The IMF supports these efforts by providing technical assistance and by catalyzing support from other sources.

\section{Differences Between the SDDS and the GDDS}

Key differences between the SDDS and the GDDS are several. (1) The SDDS prescribes specific practices that must be observed by countries that subscribe to it, whereas the GDDS provides guidelines on good practices and is generally less demanding than the SDDS. (2) SDDS subscribers must fully meet the requirements of the SDDS at the time of subscription, while the GDDS does not set fixed dates by which participants must improve their existing practices. (3) The focus of the SDDS is on data dissemination in countries that already meet high data quality standards, whereas the primary goal of the GDDS is to assist countries in developing their statistical systems through setting up plans for improvement and identifying technical assistance needs. (4) The SDDS principally covers macroeconomic and financial data (for the real, fiscal, financial, and external sectors) while including only one type of socio-demographic indicator (population); whereas the GDDS covers several types of socio-demographic data (population, health, education, and poverty), in addition to the macroeconomic and financial data covered under the SDDS, to support statistical needs of developing countries.

\section{Dissemination Standards Bulletin Board}

The DSBB plays a key role in the implementation of the IMF's data standards initiatives. It identifies publicly the member countries that subscribe to the SDDS and those that participate in the GDDS. It posts metadata of both SDDS and GDDS countries. In addition, as noted earlier, the DSBB is linked to SDDS countries' NSDPs, providing wide and easy access by the public to SDDS countries' data. The access to SDDS countries' data and metadata on the DSBB facilitates cross-country comparisons of such information, a feature that is especially important in this increasingly integrated world economy when users need to review economic and financial developments from a global perspective. The access also helps the IMF staff, as well as users, monitor subscribers' observance of the standard, ensuring its credibility. Furthermore, the DSBB includes information about the IMF Executive Board's periodic reviews of the data standards initiatives, keeping subscribing countries and the public informed of developments in the standards and fostering accountability. The Executive Board's reviews are described below. 


\section{EXECUTIVE BOARD REVIEWS SUPPORT ENHANCEMENTS AND FoSTER ACCOUNTABILITY}

The SDDS and the GDDS have been enhanced to meet the emerging needs of data users in the globalized economy. Enhancements to the SDDS, which are incorporated into the GDDS where appropriate, have been guided by decisions taken by the IMF Executive Board in its reviews of the data standards initiatives. To date, the IMF Executive Board has undertaken six such reviews, in 1997, 1998, 2000, 2001, 2003, and 2005 (see Appendix III).

As during the design and the implementation of the SDDS and GDDS, the Board reviews have been conducted in a consultative manner, both internally and externally. Typically, STA reports through Board papers on its efforts to advance the data standards initiatives and members' progress in implementing the SDDS and GDDS. The papers also identify ways to improve the standards to meet data users' emerging needs and enhance the initiatives' operational efficiency. Proposals take account of feedback received from various sources, including SDDS and GDDS country coordinators, participants in seminars, respondents in surveys, national and international agencies collaborating with STA on statistical projects, and users of the IMF's DSBB (see also next section). If specific proposals have significant resource implications, the IMF staff estimates their costs to the Fund through various means, including using feedback from the abovementioned sources. Methods in deriving such cost estimates are included in the Board papers. The Board papers are drafted by STA, reviewed by other IMF departments, and cleared by management before being issued to the Executive Board. At the time the papers are sent to the Board, copies are also made available to SDDS and GDDS country coordinators and to relevant international organizations for their information. Papers are issued several weeks before the Board's discussion so that Executive Directors can elicit comments from their constituencies on the various proposals. The papers and related press releases are posted on the IMF Web site after the Board's discussions.

The reviews have covered both the substantive and the operational aspects of the initiatives. SDDS enhancements thus far have included adding to the standard coverage of countries' foreign currency liquidity and external debt. This change came in response to the Asian financial crisis of 1997-98, which underscored the importance of such information for assessing countries' external vulnerability. Other SDDS enhancements have provided for the incorporation of new manuals and guidelines that STA has developed to improve concepts and methods for compiling countries' economic and financial data. Such manuals have included the Monetary and Financial Statistics Manual (2000), International Reserves and Foreign Currency Liquidity: Guidelines for a Data Template (2001), the Government Finance Statistics Manual (2001), the External Debt Statistics: Guide for Compilers and Users (2003), and the Compilation Guide for Financial Soundness Indicators (2003). In addition, as endorsed by the Executive Board in its fifth review of the data standards initiatives, the GDDS has been expanded to include selected social and demographic indicators as set forth in the Millennium Development Goals. 
More recently, the IMF Executive Board has supported the alignment of the SDDS and the GDDS into the Data Quality Assessment Framework (DQAF) to sharpen the focus on data quality assessment and promote good statistical practices. The DQAF provides a structure for assessing countries' existing statistical practices against best practices, including internationally accepted methodologies. The DQAF is rooted in the UN Fundamental Principles of Official Statistics and grew out of the SDDS and the GDDS. ${ }^{3}$ The DQAF incorporates good practices of the SDDS and the GDDS and reflects intensive consultations with national statistical agencies and relevant international organizations. The Executive Board formally approved its establishment in July 2003 for use in STA's work on the IMF's initiative on the Report on Observance of Standards and Codes (ROSC). The alignment of SDDS and the GDDS with the DQAF integrates STA's work on ROSC, technical assistance, and the data standards initiatives, producing a whole greater than the sum of its parts, while streamlining the IMF's support of its various data quality initiatives.

In addition, the Executive Board has endorsed steps to safeguard the credibility of the SDDS as a monitored standard so that it retains the confidence of subscribing countries, international capital markets, and the public. The Executive Board has noted that monitoring subscribers' observance is a critical factor in promoting sustained adherence to SDDS requirements, which, in turn, is the foundation for maintaining the credibility of the SDDS in capital markets and among the public. To safeguard the credibility of the SDDS through effective monitoring, the Executive Board has broadly supported requiring SDDS subscribers' use of standardized electronic reporting procedures specified by the IMF staff. Also, the Executive Board has concurred that the credibility of the SDDS will be strengthened by posting on the DSBB annual reports by the IMF staff assessing subscribing countries' observance of their SDDS undertakings, beginning in early 2007 for the year 2006 .

\section{A Comprehensive Work Program Supports Steady Implementation of THE SDDS AND THE GDDS}

The data standards have been fully integrated into the STA work program. As part of the program, STA provides technical assistance, through missions or other means, to selected countries in various regions of the world to help them put in place the practices called for by the SDDS and the GDDS. Also as part of the work program, STA regularly monitors subscribers' observance of the SDDS and tracks statistical developments in GDDS countries. STA regularly contacts SDDS and GDDS coordinators, and it has conducted numerous seminars and conferences on the data standards initiatives for data producers and users. Furthermore, STA has collaborated with the World Bank and other donor agencies on GDDS work. Some specifics follow.

\footnotetext{
${ }^{3}$ The DQAF was developed partly in response to United Nations Statistical Commission's comments in February 1999 that the usefulness of the IMF data standards initiatives would be enhanced if they incorporated explicitly specific dimensions of data quality in the standards.
} 


\section{A. Monitoring SDDS Observance}

Monitoring subscribing countries' observance of the SDDS is key to maintaining the credibility of the standard and its usefulness to policymakers, market participants, and other users. Subscribing countries are expected to observe the basic tenets and operational requirements of the standard. The IMF staff's monitoring entails reviews of the coverage, timeliness, and periodicity of data disseminated on a subscribing country's NSDP relative to the requirements of the SDDS and information shown in its metadata. The metadata are to be updated to reflect actual compilation and dissemination practices. In addition, the monitoring tracks whether a subscribing country adheres to the standardized electronic procedures the IMF staff establishes for the SDDS. The IMF staff maintains periodic communications with SDDS country coordinators on SDDS issues as they arise and assists the countries to resolve them. Procedures are in place to address nonobservance.

\section{B. Conferences, Seminars, and Other Consultations}

Following the Asian crises, the IMF undertook to strengthen the SDDS in the areas of international reserves and external debt. The issues were discussed in Board papers. In preparation for the Board papers, consultation papers on international reserves and external debt were posted on the IMF Web site in 1998 and 1999 to solicit feedback from data users and compilers. In addition, the papers were reviewed by expert groups such as the IMF Committee on Balance of Payments Statistics and the Inter-Agency Task Force on Finance Statistics. ${ }^{4}$

The IMF hosted a conference on capital-flow and debt statistics entitled "Can We Get Better Data Faster?" in February 2000, in cooperation with the Working Group on Capital Flows of the Financial Stability Forum. The conference brought together some 120 senior-level data users in the public and private sectors and compilers of statistics. STA used such feedback to enhance its work program on the data standards.

STA conducted SDDS regional seminars in Germany, Singapore, and Chile in 2000. In the same year, the Bank of Greece hosted a SDDS outreach seminar in Athens for representatives from potential SDDS countries in Central Asia, Eastern Europe, the Mediterranean, and the Middle East. In collaboration with STA, the Bulgarian authorities hosted a seminar for European SDDS coordinators in 2003. The Central Bank of Uruguay in 2004 hosted a similar seminar for SDDS country coordinators from the Western Hemisphere. In the same year, Bank Negara Malaysia sponsored a similar seminar for SDDS coordinators from Asia and the Pacific.

\footnotetext{
4 The IMF Committee on Balance of Payments Statistics advises the Fund on methodological and compilation issues in the context of balance of payments and international investment position statistics. The Inter-Agency Task Force on Finance Statistics comprises experts from a number of national and international statistical agencies; its mandate is to strengthen international statistical cooperation.
} 
To explain the benefits of sound dissemination practices and to solicit feedback from member countries and international organizations, STA in 2005 conducted seminars in Pretoria, South Africa, and in Bangkok, Thailand. The Pretoria seminar was attended by participants from 11 countries, as well as representatives from the South African Reserve Bank and the Secretariat of the Committee of Central Bank Governors of the Southern African Development Community. Participating in the Bangkok seminar were 10 potential subscribing countries in Asia and the Pacific and representatives from Thailand, the Asian Development Bank, the South East Asian Central Banks Research and Training Center, and the United Nations Economic and Social Commission for Asia and the Pacific.

In the past several years, STA organized a dozen or so regional seminars/workshops in which the GDDS was discussed with officials from statistical agencies of nearly 150 countries.

\section{Other Collaborative Efforts}

STA has collaborated on a number of GDDS projects. These projects have involved national and international agencies. For example, 34 countries participated in the first four regional GDDS projects in Africa and the Pacific. In addition, the World Bank's Statistics Capacity Building (STATCAP) lending program uses the GDDS metadata to assess statistical programs of various agencies and donors. The Partnership for Development of Statistics in the 21st Century (PARIS21) uses the GDDS to assist countries in implementing changes to advance statistical development.

In December 2004 STA conducted a survey of DSBB users through web-based forms posted on the DSBB; users provided comments on the forms. Comments have been used to enhance the capabilities of the DSBB.

To facilitate frequent consultations with SDDS coordinators, STA in 2001 launched an electronic discussion group, or e-Room. The e-Room has provided a forum for coordinators to raise issues and offer suggestions on the operation of the SDDS. The e-Room will be replaced in 2006 by a Web-based forum (Web-board).

\section{Useful Guidelines Help Participation And ObServance}

The guidelines STA has prepared to assist countries in subscribing to the SDDS or in participating in the GDDS also reflect the consultative process. The IMF released a provisional document, Guide to the Data Dissemination Standards: Module 1: The Special Data Dissemination Standard, in March 1996 to help member countries subscribe to the SDDS. In June 1998, the IMF distributed to member countries another document, The General Data Dissemination System. Key aspects of the documents were included in Board papers for which formal Board approval was sought. The documents were later released to the public and incorporated endorsements of the Executive Board. The guidelines were subsequently posted on the DSBB. 
STA has recently completed a Guide to the Special Data Dissemination Standard, 2006 (SDDS Guide 2006) to incorporate enhancements to the SDDS since its inception. The SDDS Guide 2006 has been reviewed by departments within the IMF and sent to SDDS countries for comment before publication. The SDDS Guide 2006 replaces the 1996 provisional document. It aims to assist users of the DSBB to take full advantage of the various features of the electronic bulletin board. It is also intended to promote adherence to the standard consistently among countries, guide GDDS countries to become SDDS subscribers, and assist other member countries that have not participated in the data standards to subscribe to the SDDS if they choose to do so. A revised GDDS guide will follow in due course.

\section{InCREASEd PARTicipation AdVAnCes Global Data Transparency}

Participation in the data standards initiatives by 80 percent of the IMF's membership reaffirms the importance countries place on data transparency in this increasingly globalized economy. To date, SDDS countries comprise 25 advanced economies, 12 from Central and Eastern Europe, 10 from Latin America, 6 from the Commonwealth of Independent States, 5 from developing Asia, 3 from Africa, and 1 from the Middle East. Of the 83 GDDS participating countries, about 50 percent are from Africa, 20 percent from Latin America, and the rest from Central and Eastern Europe, developing Asia, and the Middle East. Currently, STA staff is assisting a number of countries to either subscribe to the SDDS or participate in the GDDS.

Empirical studies suggest that adhering to the SDDS or the GDDS, to varying extents, helps improve a country's access to international capital markets. For instance, an STA econometric study on the borrowing costs of emerging market and developing countries over the past decade and a half found strong and consistent evidence of discounts for sovereign bond issuers participating in the GDDS, as well as for countries subscribing to the SDDS. The discounts amounted to about 8 percent for GDDS participants and 20 percent for SDDS subscribers, or the equivalent of about 20 and 50 basis points, respectively. ${ }^{5}$

In conclusion, the consultative process used in the implementation of the data transparency standards has allowed for the development of a coherent program that takes account of countries' capabilities, delineates clearly their responsibilities and those of the IMF, and establishes effective monitoring procedures to ensure the credibility of the standards for policymakers, capital markets, and the public. The approach also has provided checks and balances and fostered accountability. The initiatives may provide insights into ways to promote other similar international standards.

\footnotetext{
5 See John Cady, "Does SDDS Subscription Reduce Borrowing Costs on Emerging Market Economies?" IMF Working Paper 04/58 (Washington: International Monetary Fund).
} 


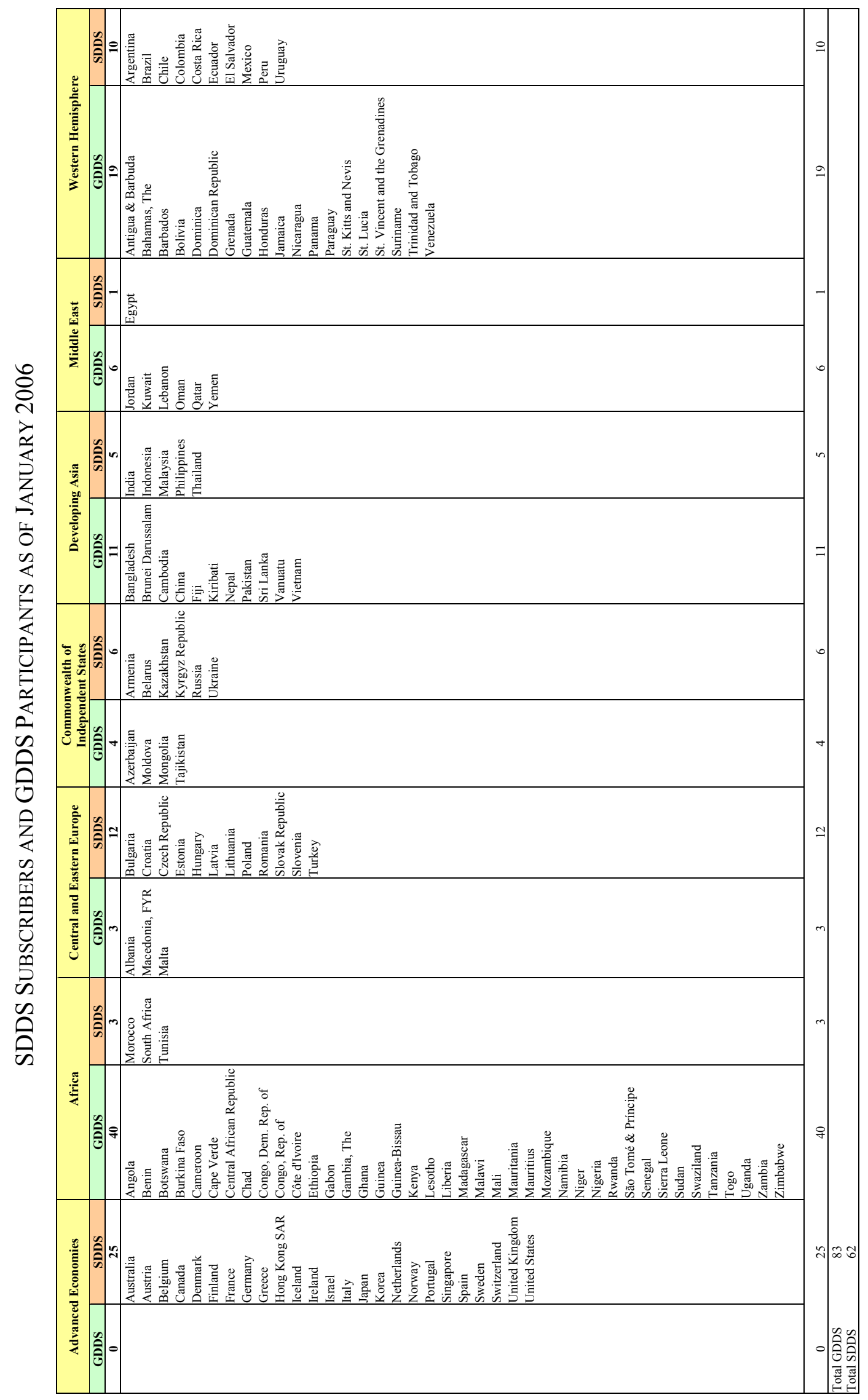




\section{Key Dimensions AND Elements OF THE SDDS}

The four dimensions of the SDDS are shown in bold, and corresponding monitorable elements are shown in italics.

1. The data: coverage, periodicity, and timeliness: Comprehensive economic and financial data, disseminated on a timely basis, are essential to the transparency of macroeconomic performance and policy. Countries subscribing to the Standard are to:

- $\quad$ Disseminate the prescribed categories of data with the specified periodicity and timeliness.

2. Access by the public: Dissemination of official statistics is an essential feature of statistics as a public good. The SDDS calls for providing the public, including market participants, ready and equal access to the data. Countries subscribing to the Standard are to:

- $\quad$ Disseminate in advance release calendars for the data.

- $\quad$ Release the data to all interested parties simultaneously.

3. Integrity: To fulfill the purpose of providing the public with information, official statistics must have the confidence of their users. In turn, confidence in the statistics ultimately becomes a matter of confidence in the objectivity and professionalism of the agency producing the statistics. Transparency of its practices and procedures is a key factor in creating this confidence. The SDDS requires subscribing countries to:

- $\quad$ Disseminate the terms and conditions under which official statistics are produced, including those relating to the confidentiality of individually identifiable information.

- Identify internal government access to data before release.

- Identify ministerial commentary on the occasion of statistical releases.

- $\quad$ Provide information about revision and advance notice of major changes in methodology.

4. Quality: A set of standards that deals with the coverage, periodicity, and timeliness of data must also address the quality of statistics. Although quality is difficult to judge, monitorable proxies, designed to focus on information the user needs to judge quality, can be useful. The SDDS requires subscribing countries to:

- $\quad$ Disseminate documentation on methodology and sources used in preparing statistics.

- $\quad$ Disseminate component detail, reconciliations with related data, and statistical frameworks that support statistical cross-checks and provide assurance of reasonableness. 


\section{KEY ENHANCEMENTS TO THE SDDS}

When the SDDS was established in March 1996, the IMF's Executive Directors emphasized that the implementation of the SDDS should be flexible and that the Standard should evolve over time to ensure that it incorporates best practices for data dissemination. Since the inception of the data standards initiative, the IMF's Executive Board has undertaken six reviews $(1997,1998,2000,2001,2003$, and 2005), ensuring the ability of the SDDS to adapt to changing circumstances. These changes have responded to users' data needs associated with assessing external vulnerabilities. They also have involved data quality improvements relating to the adoption of new, internationally accepted methodological standards. Key enhancements of the SDDS as endorsed by the Executive Board are highlighted below (the numbers shown in brackets refer to the year of the review):

- $\quad$ Developed procedures for modifying the SDDS. (1997)

- $\quad$ Prescribed hyperlinks from the DSBB to the NSDP. (1998)

- $\quad$ Prescribed the dissemination of the Data Template on International Reserves and Foreign Currency Liquidity. (1998)

- $\quad$ Endorsed IMF staff's systematic monitoring of subscribing countries' observance of the SDDS. (2000)

- $\quad$ Adopted a three-year transition period (ending in March 2003) for prescribing a new SDDS data category on external debt with quarterly periodicity and timeliness; the data are to cover external debt of the general government, the monetary authorities, the banking sector, and all other sectors of a country. (2000)

- $\quad$ Lengthened the lag for disseminating annual data on international investment position (IIP) from six months to nine months and introduced a timetable requiring subscribing countries to begin disseminating IIP data. (2000)

- $\quad$ Confirmed procedures to address instances of nonobservance of the SDDS. (2001)

- $\quad$ Endorsed the update of the SDDS following the publication of the IMF's Monetary and Financial Statistics Manual (MFSM) published in 2000 and the IMF's Government Finance Statistics Manual 2001 (GFSM 2001); the MFSM (2000) provides a conceptual framework for presenting monetary and financial statistics to assist monetary policy formulation and monitoring and the assessment of financial sector stability; the GFSM 2001 recommends the reporting of government finance and related activities on an accrual basis and extending such reporting to cover the public sector, where applicable. (2001)

- $\quad$ Supported the use of a common transmission standard for disseminating and exchanging statistical information (including metadata) on the Internet among international organizations and their member countries, as being developed under the Statistical Data and Metadata Exchange (SDMX) Initiative, to which the IMF contributes. (2001)

- $\quad$ Emphasized increased subscription to the SDDS by member countries. (2003)

- Introduced a targeted timeliness flexibility option for central government operations if quarterly accrual-based data (conforming with the GFSM 2001 or equivalent regional standards) on general government operations are disseminated with a lag of no more than a quarter. (2003)

- Made observance of automated reporting procedures an SDDS undertaking to enhance operational efficiency and effectiveness of monitoring, to sustain the credibility of the SDDS. (2003)

- $\quad$ Supported the posting of an annual assessment report covering each subscribing member's SDDS observance, beginning in 2007 for the year 2006. $(1998,2005)$

- $\quad$ Endorsed the use of the Data Quality Assessment Framework (DQAF) to present SDDS metadata to integrate the SDDS with IMF's work on Data Modules on Report of Observance of Standards and Codes and technical assistance in statistical areas. (2005)

- $\quad$ Encouraged subscribing countries to deepen their metadata on oil and gas activities and products. (2005) 